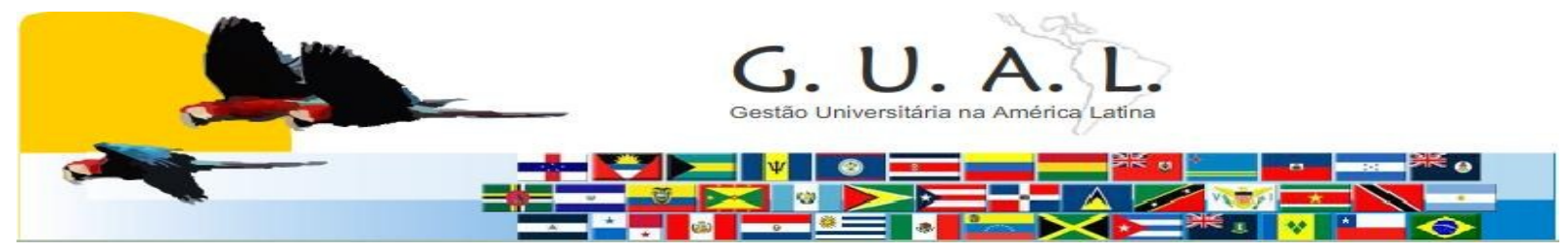

ISSN 1983-4535

\title{
A TRANSIÇÃO DE CONTRIBUIDOR INDIVIDUAL PARA LÍDER: A EXPERIÊNCIA VIVIDA PELO PROFESSOR UNIVERSITÁRIO
}

THE TRANSITION FROM INDIVIDUAL CONTRIBUTOR TO LEADER: THE LIVED EXPERIENCE OF THE UNIVERSITY PROFESSOR

Fabiula Meneguete Vides da Silva, Doutora Universidade Federal da Grande Dourados fabiulamv@yahoo.com.br

Cristiano José Castro de Almeida Cunha, Doutor Universidade Federal de Santa Catarina 01cunha@gmail.com

Recebido em 24/outubro/2011

Aprovado em 08/março/2012

Sistema de Avaliação: Double Blind Review

Esta obra está sob uma Licença Creative Commons Atribuição-Uso. 


\title{
RESUMO
}

Este trabalho objetiva compreender o processo de transição do contribuidor individual (professor) para líder (reitor ou pró-reitor) em universidades. A abordagem fenomenológicohermenêutica de van Manen (1990) foi utilizada a fim de retomar os principais temas desta experiência. Seis ex-gestores universitários emprestaram suas experiências vivenciadas em universidades pertencentes à Associação Catarinense das Fundações Educacionais (ACAFE), através das entrevistas em três tempos preconizadas por Seidman (1998), realizadas entre maio de 2009 e março de 2010. Recorrendo às entrevistas transcritas, foi possível resgatar nove grandes temas centrais, que representam as experiências que os professores entrevistados viveram: a estrutura universitária: um dos desafios; a agenda do líder universitário; o relacionamento interpessoal: a diversidade nas e das relações; a falta da pesquisa e da sala de aula; mudando o olhar: a necessidade da visão do conjunto; buscando qualificação profissional: "um divisor de águas"; o tempo: "meu inimigo número um"; o ambiente de trabalho; e sofrendo. Os dados encontrados revelam temas úteis para a compreensão da experiência vivida na transição de professores para líderes universitários, contribuindo para pensarmos em políticas de recursos humanos, a fim de minimizarmos os aspectos negativos vividos pelos professores, como também para ampliarmos as pesquisas que levem em conta a temática da transição nas universidades.

Palavras-chave: Contribuidor individual. Líder universitário. Transição. Experiência vivida.

\begin{abstract}
This study aims to understand the process of transition from individual contributor (teacher) to lead (dean) in universities. The phenomenological-hermeneutic approach of van Manen (1990) was used to recapture the main themes of this experience. Six former university administrators lent their experiences at universities belonging to the Santa Catarina Association of Educational Foundations (ACAFE), through interviews in three stages suggested by Seidman (1998), conducted between May 2009 and March 2010. Drawing on interviews transcribed, it was possible to rescue nine major central themes that represent the experiences that teachers interviewed lived: the structure of universities: one of the challenges; the agenda of the university leader; interpersonal relationships: the diversity in relationships; lack research and the classroom; changing the look: the need for clear focus; seeking professional qualification: "a watershed"; the time: "my number one enemy"; the work environment; and suffering. Data reveal themes useful for understanding the lived experience of teachers in the transition to university leaders, contributing to think about human resources policies in order to minimize the negative aspects experienced by teachers, but also to broaden the research that take into account the theme of transition in the universities.
\end{abstract}

Keywords: Individual contributor. University leader. Transition. Lived experience. 


\section{CONSIDERAÇÕES INICIAIS}

As transições são experiências humanas carregadas de emoções, desafios, perdas e oportunidades. Às vezes, elas são ignoradas, ou seu impacto é minimizado pelos gerentes. A realidade é que elas afetam o desempenho das pessoas e o funcionamento das organizações (NININGER; ARDITTI, 2004).

Estudos focados na transição estão relacionados ao processo de aposentadoria de executivos (DE VRIES, 1988), perda de emprego (LATACK; KINICKI; PRUSSIA, 1995; KINICKI; PRUSSIA; MCKEE-RYAN, 2000; ZIKIC; RICHARDSON, 2007), transição de gerente de uma organização para uma atividade autônoma (DUBERLEY; MALLON; COHEN, 2006), transição de contribuidor individual para líder (PEARCE II, 1982; KONCZAK, 1994; THOMAS, 1999; HOWARD, 2003; HILL, 2003), ou transição de líder para contribuidor individual (SILVA, 2011).

$\mathrm{Na}$ literatura acadêmica, encontramos pesquisas sobre o processo de tornar-se gerente, bem como descrições e interpretações acerca dos primeiros meses num cargo de gerência (PEARCE II, 1982; KONCZAK, 1994; THOMAS, 1999; HOWARD, 2003; HILL, 2003). Contudo, são poucos os estudos que enfocam esse processo vivenciado por professores universitários, apesar da importância significativa dessa experiência na vida desses profissionais.

Na universidade, é fortemente presente o aspecto da temporariedade do exercício do cargo de gerência. O docente pode, ao longo de sua carreira universitária, assumir uma coordenação de curso, uma chefia de departamento, pró-reitoria ou reitoria. Após essa experiência, ele pode retornar à sua função original, o que, na maioria das vezes, significa voltar a ser professor, sem as responsabilidades típicas da gestão universitária. Não obstante o fato de essas transições serem rotineiras nas universidades, elas merecem maior compreensão.

Neste trabalho, o "líder" está representado pelo reitor ou pró-reitor universitário, e o "contribuidor individual", pelo professor. O contribuidor individual é um especialista, um produtor ou um profissional. Sua principal responsabilidade é "realizar tarefas técnicas específicas; sua colaboração para com a organização [...] [é] individual, dependendo acima de tudo de sua competência, experiência e energia" (HILL, 2003, p. 3). São funcionários que executam seu trabalho e não possuem responsabilidade de supervisionar o trabalho de outras pessoas. Por um lado, como contribuidor individual, o professor é responsável apenas por 
suas atividades, realizando tarefas específicas e programadas, não sendo responsável pelas atividades dos demais colegas. Por outro lado, como líder, o reitor ou o pró-reitor exercem influência sobre as atividades de várias pessoas, possuindo uma agenda imprevisível e dependente de necessidades alheias.

Objetivando compreender o significado da experiência vivida pelo professor universitário no processo de transição de contribuidor individual para líder entrevistamos seis ex-gestores universitários de universidades pertencentes à Associação Catarinense das Fundações Educacionais (ACAFE).

\section{TRANSIÇÃO}

De acordo com Nininger e Arditti (2004), as transições que afetam as pessoas enquadram-se em duas categorias. A primeira delas, foco do estudo desta pesquisa, é o das transições no local de trabalho, estando relacionadas às carreiras profissionais. Essa categoria inclui a entrada no mercado de trabalho, as promoções, as mudanças de funções e, por último, a saída de um emprego remunerado, por opção própria ou por força das circunstâncias. A segunda categoria, a das transições pessoais, inclui transições positivas e também negativas, tais como um casamento (férias planejadas), o nascimento ou adoção de um filho (licença maternidade/paternidade), uma doença debilitante (licença médica por motivo de doença), a perda de um parente (licença por motivo de óbito de um familiar).

Qualquer que seja a transição, ela envolve questões que devem ser tratadas tanto pelas pessoas diretamente afetadas quanto pelas organizações nas quais elas trabalham (SARGENT; SCHLOSSBERG, 1988; NININGER; ARDITTI, 2004).

Schlossberg (1981), discute o processo de transição e através de seus estudos elencou múltiplos aspectos que o facilitam ou dificultam. Esses aspectos culminaram em um modelo analítico de adaptação à transição, que considera as características individuais e as de ocorrências externas. Este modelo, conforme apresentado na figura 1, é baseado em pressupostos de teorias do curso de vida e em vários outros modelos de transição, e postula três principais conjuntos de fatores que influenciam a adaptação à transição: as características da transição em si mesma, as características dos ambientes de pré e pós-transição e as características do indivíduo (SCHLOSSBERG, 1981). 


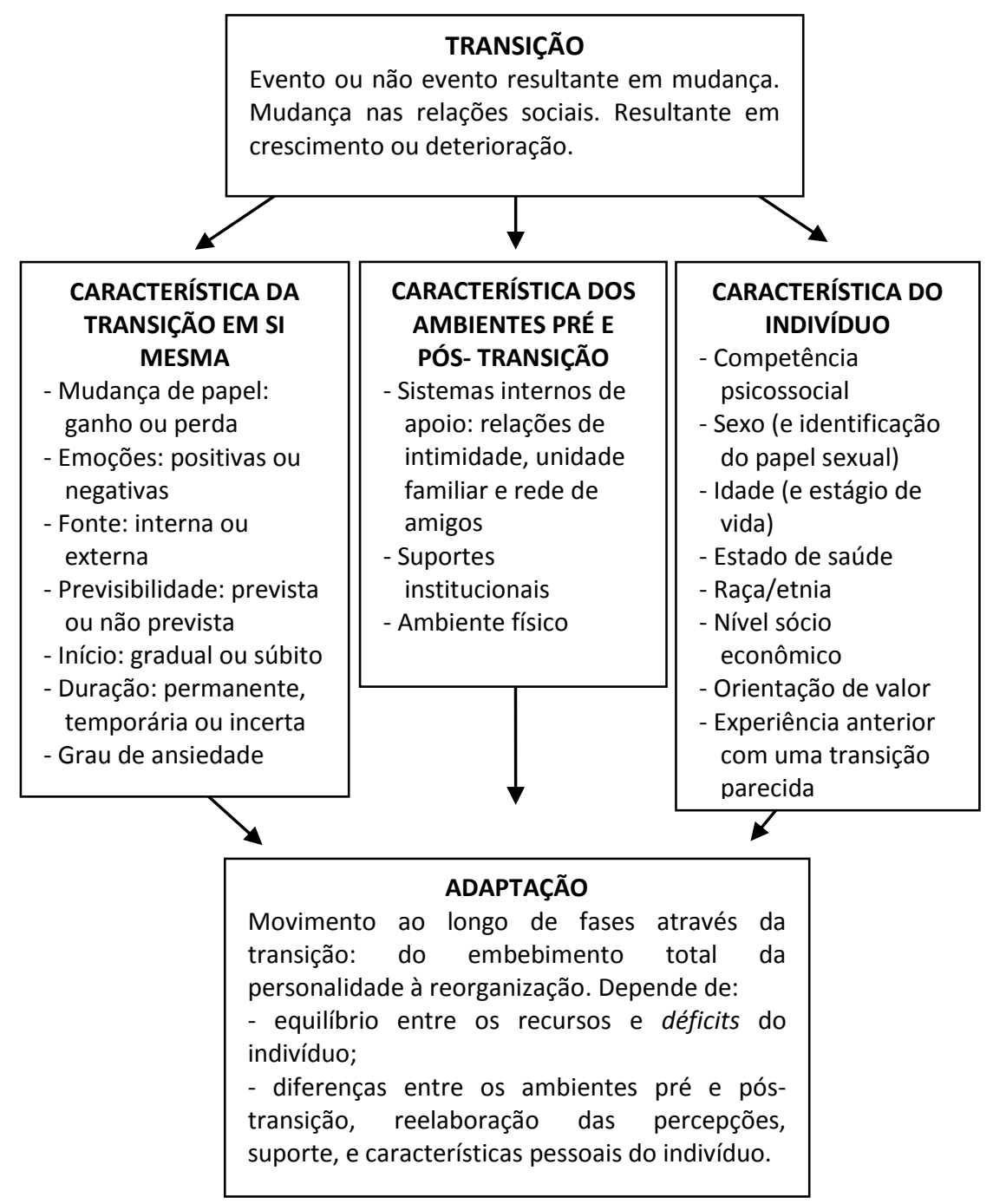

Figura 1 Modelo para análise da adaptação humana à transição.

Fonte: Adaptado de Schlossberg (1981).

Schlossberg (1981) entende que não é a transição em si que merece importância, mas como esta transição se ajusta ao momento, à situação e ao estilo de cada pessoa na superação da transição. Embora cada fator ou variável seja descrito como unidade independente, dinamicamente interagem entre si, resultando na adaptação ou não adaptação. A adaptação decorre do equilíbrio entre recursos e déficits. Quando os recursos excedem os déficits, a adaptação é facilitada, mas quando os déficits excedem os recursos, a adaptação se torna mais difícil. Dependendo da transição e do grupo em observação, diferentes variáveis podem ter diferentes proeminências.

Schlossberg (1981) vai além e acaba por se configurar um ícone nos estudos de transição, já que leva em consideração - além das próprias características da transição - as características dos ambientes de pré e de pós-transição e as do indivíduo. 


\subsection{O reitor como líder universitário}

Embora sejam comuns estudos sobre a gestão universitária, existe uma carência de literatura nacional relacionada ao processo de professores se tornarem gestores em universidades (SILVA, 2000; ÉSTHER, 2007; ÉSTHER; MELO, 2007; MORAES, 2008). Cunha (1999, p. 125) ressalta que "os estudos de gestão na universidade brasileira são extremamente acanhados".

O trabalho de Kerr (1982) constitui um dos mais citados pelos estudiosos da gestão universitária e traz uma compreensão da figura do reitor: é um personagem de várias faces, que desempenha diferentes papéis, atendendo aos mais diversos stakeholders.

Corroborando com os estudos de Kerr (1982), Hesburgh (1982), ao descrever as dificuldades enfrentadas por reitores em suas gestões, traça um perfil idealizado dessa função, ou seja, cria características diversas, impossíveis de serem possuídas por uma única pessoa.

No Brasil, Finger (1986, 1988), Cunha (1999), Trigueiro (1999) e Tachizawa e Andrade (1999) destacam que a universidade não pode ser gerenciada como se fosse uma empresa, utilizando-se, por exemplo, de métodos da qualidade total empresarial, o que também não significa que não se deva considerar a qualidade como um valor importante, sendo, por isso, necessário o estabelecimento do significado de qualidade na instituição. Finger (1988) ressalta que nem sempre a transferência de técnicas de gestão empresarial pode ou deve apresentar os mesmos resultados (que apresentam nas empresas) em uma instituição acadêmica.

Tachizawa e Andrade (1999) também ressaltam a necessidade de se pensar a qualidade no âmbito das Instituições de Ensino Superior (IES), por meio da estruturação de critérios de excelência. Tachizawa e Andrade (1999, p. 16) salientam, ainda, que:

[...] uma instituição de ensino possui peculiaridades que a distinguem de outras formas de organização, quer seja pública ou privada, razão pela qual não é salutar que ela seja gerida tal qual uma organização que pertença a setores econômicos com características diferentes das suas.

Rezende (1982) apresenta uma discussão, em que critica a quantidade em detrimento da qualidade. A quantificação dos resultados apresenta-se em forma de estatísticas que relatam o número de alunos matriculados, o número de teses e dissertações defendidas, sem demais preocupações com a qualidade do ensino.

Rezende (1982) destaca outro fator dificultador da administração universitária: “com muita frequência, temos visto engenheiros, físicos, advogados competentes serem propostos 


\section{A TRANSIÇÃO DE CONTRIBUIDOR INDIVIDUAL PARA LÍDER: A EXPERIÊNCIA VIVIDA PELO PROFESSOR UNIVERSITÁRIO}

como reitores, diretores, chefes, coordenadores de outros setores, com o argumento de que demonstraram grande competência em suas áreas próprias de atuação". (REZENDE, 1982, p. 6)

Essa discussão levanta a questão de que os atuais administradores da educação, na maior parte dos casos, não foram formados para desempenhar papéis de gestores nas Instituições de Ensino em que trabalham. (RIZZATTI; RIZZATTI JR.; SARTOR, 2004),

Das discussões apresentadas, podemos identificar alguns dos problemas enfrentados pela administração universitária: a maioria dos administradores universitários não foi formada para essa tarefa, sendo obrigada, dessa forma, a improvisar seus papéis; esses administradores foram formados para outro tipo de administração, o de empresas, por exemplo.

\subsection{Tornar-se gestor universitário: estudos empíricos}

Para fins desta pesquisa, a gestão se constitui como uma atividade acadêmica, mas não como essência do trabalho do professor, pois o que define o trabalho acadêmico do professor universitário é o ensino, a pesquisa e extensão. A gestão é considerada uma atividade de cooperação do professor junto à instituição de ensino superior.

Quanto aos estudos que investigaram o processo de tornar-se gerente universitário, podemos destacar o de Moraes (2008), que buscou compreender as trajetórias das mulheres que se tornaram reitoras de Instituições de Ensino Superior em Santa Catarina. Como resultado dessa pesquisa, as trajetórias dessas mulheres foram contadas a partir de sete grandes categorias: as mulheres e seu tempo (espaços possíveis, caminhos limitados); pequenas grandes rebeldias; as mulheres e a caminhada nas/das universidades catarinenses; encontros e desencontros; encantos e desencantos do caminho trilhado; continuidades e descontinuidades; construindo uma/a história.

Essas categorias fundamentaram a narrativa sobre as trajetórias das mulheres e desvendaram que: a) as mulheres entrevistadas transitaram por espaços históricos e culturalmente definidos para as mulheres de sua época, como o curso normal, a faculdade na área de ciências humanas, o magistério e a família; b) elas foram movidas por ideais construídos durante uma época de opressão e autoritarismo; elas desejaram ser mães, professoras, esposas; desejaram coisas que não puderam ser/ter; tiveram medo, choraram, tiveram alegrias e também decepções; e por fim, c) estabeleceram relações específicas e importantes com suas mães, com seus esposos, com seus corpos e com o poder. 


\section{A TRANSIÇÃO DE CONTRIBUIDOR INDIVIDUAL PARA LÍDER: A EXPERIÊNCIA VIVIDA PELO PROFESSOR UNIVERSITÁRIO}

Objetivando identificar as concepções de coordenadores de curso sobre seus papéis no sistema de relações que constitui uma universidade, Piazza (1997) relatou o despreparo e a necessidade de aprendizagem relacionada ao exercício da função, bem como a falta de clareza das próprias funções. Esses resultados reafirmam os achados na literatura da área, que indicam que esses dirigentes não estão familiarizados com a gestão nem preparados para assumi-la.

Os estudos de Marra e Melo (2003) objetivaram descrever as práticas de gestão de chefes de departamento e coordenadores de curso. A análise dos relatos dos entrevistados demonstrou que as funções dos coordenadores de curso e chefes de departamento vão além das relativas ao planejamento, organização, direção e controle. Suas funções são executadas sem planejamento, imperando o imediatismo e improviso. Além disso, às atividades dos gerentes universitários somam-se as de docente e pesquisador, o que lhes acarreta uma sobrecarga de trabalho. Para cumprir suas funções, eles aumentam o número de horas trabalhadas, levam trabalho para casa, diminuem as atividades de pesquisa e de docência, e contam com o auxílio dos estudantes de pós-graduação, seus orientandos, para conciliar todas as atividades.

A pesquisa desenvolvida por Silva (2000) buscou compreender os processos de aprendizagem adotados por professores no exercício do cargo de diretores, em onze Unidades Universitárias da Universidade Federal de Santa Catarina (UFSC). Através do estudo de casos, com abordagem qualitativa, observou-se que os professores apresentam significativas diferenças nos processos de aprendizagem, dependendo da forma como iniciaram as suas vidas profissionais. Para todos os professores pesquisados, independentemente do início da sua trajetória profissional, o processo de aprendizagem caracterizou-se por ser informal e autodirecionado, realizando-se apenas no trabalho, através da ação e da interação social.

Heerdt (2002), em seu trabalho, procurou identificar as competências essenciais dos coordenadores de uma organização universitária.

A autora entende que competências adequadas fornecem suporte às atividades de gestão dos cursos de graduação, melhorando seu desempenho e fornecendo subsídios às atividades de recursos humanos. Nos relatos dos professores entrevistados, percebe-se que os papéis considerados importantes pelos coordenadores são os da comunicação, interação, relacionamento interpessoal, liderança, planejamento e conhecimento. A pesquisa indicou, ainda, algumas áreas de conhecimento deficitárias, mas consideradas necessárias ao bom desempenho do curso, quais sejam: técnicas de administração, especialmente em gestão, 


\section{A TRANSIÇÃO DE CONTRIBUIDOR INDIVIDUAL PARA LÍDER: A EXPERIÊNCIA VIVIDA PELO PROFESSOR UNIVERSITÁRIO}

como planejamento e questões contábeis e financeiras; conhecimento da estrutura existente; formação didático/pedagógica; desenvolvimento de projetos; e, finalmente, conhecimento sobre órgãos de financiamento. Mais uma vez, o conhecimento múltiplo e a visão do todo se apresentam como um papel importante a ser desempenhado pelo responsável pela gestão.

Decorre, então, a partir das evidências empíricas listadas nessas pesquisas, que a literatura que discute a função gerencial de docentes de universidade brasileiras (HEERDT, 2002; SILVA, 2002; SILVA; MORAES, 2002; MARRA; MELO, 2003, 2005; SILVA; MORAES; MARTINS, 2003; ÉSTHER, 2007; KANAN, 2008; SILVA, 2011) ressalta que em suas atividades prevalecem a improvisação, o imediatismo, a falta de planejamento, características essas condizentes com a literatura já apresentada que discute as atividades dos gerentes contemporâneos.

A literatura pesquisada ressalta também alguns aspectos importantes que merecem atenção na gestão desse tipo de organização, quais sejam: a "multiplicidade" de papéis exercidos pelos gestores universitários; a "temporariedade" com que os papéis de gerência são exercidos - o docente é levado a uma chefia, quer no nível de departamento ou de pró-reitoria, por prazo determinado, e ele volta à função de professor por um prazo também conhecido; o desconhecimento e a não preparação dos indivíduos para um cargo de gestão, dando espaço ao "amadorismo", conforme citado por Figueiredo (1992).

\section{METODOLOGIA UTILIZADA}

Este estudo está situado no paradigma interpretativo que, segundo Morgan (1980), baseia-se na visão de que o mundo social tem um status ontológico precário, e que a realidade social não existe num senso concreto, mas é o produto das experiências subjetivas e intersubjetivas do indivíduo e interpretativo voltado à visão subjetiva.

Com o objetivo de compreender o significado da experiência vivida pelo professor universitário no processo de transição de contribuidor individual para líder, por meio de uma abordagem qualitativa, utilizamos a abordagem fenomenológico-hermenêutica (VAN MANEN, 1990).

Para van Manen (1990), o objetivo final da ciência humana fenomenológica é um esforço concentrado da reflexão, em função de um retorno a uma experiência direta e primordial com o mundo circundante. A compreensão da experiência vivida envolve uma prática textual: a escrita reflexiva, a qual nós chamamos de pesquisa social. É o estudo fenomenológico e hermenêutico da existência humana: fenomenológico, porque é um estudo 
descritivo da experiência vivida (fenômeno), na tentativa de enriquecer a experiência vivida compreendendo seu significado; hermenêutico, porque é um estudo interpretativo de expressão e objetivação (textos) da experiência vivida, na tentativa de determinar o seu significado.

Seis ex-gestores universitários emprestaram suas experiências, vivenciadas em universidades pertencentes à Associação Catarinense das Fundações Educacionais (ACAFE), através das entrevistas em três tempos preconizadas por Seidman (1998), realizadas entre maio de 2009 e março de 2010. Essa técnica reúne e explora as falas dos entrevistados, permitindo ao pesquisador compreender profundamente o significado do fenômeno humano. Esse tipo de coleta de dados procura estimular a pessoa entrevistada a descrever e, sobretudo, refletir sobre a sua experiência no contexto de sua vivência (SEIDMAN, 1998). Os nomes utilizados a fim de identificar os sujeitos significativos deste estudo são fictícios, a fim de garantir seu anonimato.

Os sujeitos significativos deste estudo foram escolhidos de acordo com o método de saturação de dados. O fechamento amostral por saturação teórica é compreendido como a suspensão de inclusão de novos sujeitos quando os dados obtidos apresentam, na avaliação do pesquisador, uma certa redundância ou repetição, não sendo considerado relevante persistir na coleta de dados. Isto quer dizer que as informações fornecidas pelos novos participantes do estudo pouco acrescentariam ao material já obtido, não mais contribuindo significativamente para o aperfeiçoamento da reflexão fundamentada nos dados que estão sendo coletados (GLASER; STRAUSS, 1967).

Após a realização das entrevistas, partimos para sua transcrição, gerando as descrições experienciais. A transcrição configurou-se como um novo desafio de conhecimento e aprendizado. De posse desses transcritos, debruçamo-nos sobre as entrevistas, lendo e relendo-as para identificar temas analisáveis. Para van Manen (1990), a tematização é uma maneira de controlar e dar ordem tanto para a pesquisa quanto para a escrita. A delimitação de temas na pesquisa fenomenológica é uma maneira para encontrar significados do mundo vivido pelo pesquisado, e é realizada tendo como base o estabelecimento de categorias, conforme já destacado anteriormente.

No processo de análise, o tema reflete uma das possíveis direções para o alcance da essência do fenômeno, busca dar forma ao que não tem forma, descreve o conteúdo do fenômeno temporariamente, objetivando alcançar sua essência. O tema é uma redução do fenômeno para chegar à sua essência, representa de forma simplificada o que foi dito, o que 
foi vivido. O tema desvenda o significado, representando uma forma de ler o que se encontra nas entrelinhas do texto transcrito das entrevistas.

\section{OS SUJEITOS E SUAS HISTÓRIAS}

Participaram deste estudo quatro professores e duas professoras, que viveram a experiência da transição de professores para reitores e pró-reitores. Embora nunca tenham deixado de ser professores, viveram um período, em suas carreiras, em que assumiram a responsabilidade pela gestão universitária.

Para resgatar essas experiências, apresentamos, em breves linhas, suas trajetórias de vida, a partir dos aspectos mais relevantes e marcantes de suas caminhadas. Com o objetivo de facilitar a leitura do texto, sintetizamos, no quadro 2, alguns dados importantes de suas histórias.

Os nomes utilizados a seguir são fictícios, a fim de garantir o anonimato dos sujeitos significativos do estudo.

\begin{tabular}{|c|c|c|c|c|c|c|}
\hline & Miguel & Julia & Lucas & Rafael & Samuel & Beatriz \\
\hline Estado civil & Casado & Casada & Casado & Casado & Casado & Casada \\
\hline $\mathbf{N}^{\circ}$ de filhos & 1 & 2 & 2 & 2 & 3 & 3 \\
\hline $\begin{array}{c}\text { Área de } \\
\text { formação }\end{array}$ & $\begin{array}{c}\text { Ciências } \\
\text { Exatas e } \\
\text { Tecnoló- } \\
\text { gicas }\end{array}$ & $\begin{array}{c}\text { Ciências } \\
\text { Humanas e } \\
\text { Sociais }\end{array}$ & $\begin{array}{c}\text { Ciências } \\
\text { Biológicas }\end{array}$ & $\begin{array}{c}\text { Ciências } \\
\text { Exatas e } \\
\text { Tecnoló-gicas }\end{array}$ & $\begin{array}{c}\text { Ciências } \\
\text { Exatas e } \\
\text { Tecnoló-gicas }\end{array}$ & $\begin{array}{c}\text { Ciências } \\
\text { Humanas e } \\
\text { Sociais }\end{array}$ \\
\hline $\begin{array}{c}\text { Ano da } \\
\text { Graduação }\end{array}$ & 1990 & 1989 & 1975 & 1983 & 1989 & 1971 \\
\hline $\begin{array}{c}\text { Término do } \\
\text { mestrado }\end{array}$ & 2000 & 1993 & 1979 & - & 1992 & 1982 \\
\hline $\begin{array}{c}\text { Término } \\
\text { doutorado }\end{array}$ & - & 2000 & - & - & 1997 & 2007 \\
\hline $\begin{array}{c}\text { Ano em que } \\
\text { entrou na IES } \\
\text { da qual depois } \\
\text { foi reitor ou } \\
\text { pró-reitor }\end{array}$ & 1991 & 1992 & 1976 & 1985 & 1998 & 1986 \\
\hline $\begin{array}{c}\text { Época em que } \\
\text { foi reitor ou } \\
\text { pró-reitor }\end{array}$ & $2006-2008$ & $2003-2006$ & $2002-2006$ & $2002-2006$ & $2002-2006$ & $1998-2002$ \\
\hline
\end{tabular}

QUADRO 2 Algumas informações sobre os professores que vivenciaram a transição de reitores e próreitores para a sala de aula.

Fonte: Silva (2011). 


\subsection{Significados da experiência vivida pelo ser professor universitário, na sua transição para a reitoria ou pró-reitoria}

Os professores universitários entrevistados, em sua maioria, emergiram como gestores através de um processo de eleição, para o qual foram indicados devido ao reconhecimento da comunidade acadêmica pelas suas trajetórias de trabalho e dedicação à universidade.

$\mathrm{Na}$ carreira universitária, quando passam de professores (colaboradores individuais) para reitores e pró-reitores (líderes), eles não são mais responsáveis apenas por seus alunos e pesquisas, já que ser líder universitário envolve também a coordenação de seus pares, o tratamento de conflitos, a supervisão de atividades diversas, em detrimento da realização direta de seus trabalhos técnicos.

Lendo as histórias desses professores que assumiram os cargos mais elevados e de maior responsabilidade nas instituições de ensino superior, percebemos que o fato de estarem em tais funções significou, para eles, uma realização profissional e uma enorme vontade de redirecionar os modelos de gestão, para que as universidades comunitárias assumidas continuassem cumprindo seu papel social.

A partir das entrevistas realizadas, percebemos que a perspectiva de endeusamento da figura de líder universitário não está presente somente na literatura, mas também na compreensão desses ex-gestores: "Ser líder significa estar à frente, significa um ponto de apoio, um elemento articulador dos potenciais da equipe, [...]. O líder deve possuir várias virtudes para conseguir agregar todos”. (JULIA)

Kerr (1982) e Bennis (1999) são exemplos de autores que destacam diversas virtudes que devem fazer parte da personalidade dos líderes universitários, além de discutirem a forma como estes atuam. Os autores destacam que ser líder universitário é estar em contato direto com os estudantes, colegas docentes, comunidade externa; é ser um administrador idôneo; é ser um porta-voz para a imprensa, é ser exemplo nas relações familiares.

O perfil apregoado consiste no mito do líder-herói, o grande homem (PEARCE; CONGER, 2003), ou seja, uma pessoa com dotes especiais, tais como descreve a teoria dos traços (STOGDILL, 1974).

Recorrendo às entrevistas transcritas, foi possível resgatar nove grandes temas centrais, que representam as experiências que os professores entrevistados viveram como reitores e pró-reitores: a) a estrutura universitária: um dos desafios; b) a agenda do líder universitário; c) o relacionamento interpessoal: a diversidade nas e das relações; d) a falta da pesquisa e da sala de aula; e) mudando o olhar: a necessidade da visão do conjunto; f) 


\section{A TRANSIÇÃO DE CONTRIBUIDOR INDIVIDUAL PARA LÍDER: A EXPERIÊNCIA VIVIDA PELO PROFESSOR UNIVERSITÁRIO}

buscando qualificação profissional: "um divisor de águas"; g) o tempo: "meu inimigo número um"; h) o ambiente de trabalho; e i) sofrendo. Esses temas são redigidos separadamente, mas, ao mesmo tempo, são intercambiáveis, fazendo parte da experiência vivida pelo líder universitário.

\subsubsection{A estrutura universitária: um dos desafios}

A natureza jurídica das instituições comunitárias, bem como as especificidades das pró-reitorias, foram questões que chamaram a atenção dos reitores e pró-reitores, assim que assumiram o cargo. Na posição de professores, tinham uma noção limitada a respeito do que encontrariam ao assumirem a liderança universitária. Somente na prática, no dia a dia do trabalho como gestores, perceberam mais claramente essas características.

As universidades onde os professores em estudo assumiram cargos de reitor ou próreitor integram o Sistema ACAFE - Associação Catarinense das Fundações Educacionais. Essas universidades são entidades públicas de direito privado, pertencentes ao governo dos municípios onde está situado seu campus sede. São entidades filantrópicas, instituídas de acordo com as leis federais $\mathrm{n}^{\circ} \mathrm{s}$. 3.577/59, 7.644/84, 8.742/93, 1.493/94, e a Resolução do Conselho Nacional de Assistência Social (CNAS) nº66/96.

As universidades fundacionais catarinenses são mantidas por Fundações, que, por sua vez, são pessoas jurídicas patrimoniais de direito privado, sem objetivo de lucro, que se organizam para contribuir com a elaboração e execução de projetos universitários de pesquisa e extensão, e também para a oferta de diferentes cursos de educação superior.

No período em que foram líderes destas instituições universitárias, os ex-gestores viveram inúmeros desafios, relacionados especificamente à natureza das universidades fundacionais, tais como a atuação em um mercado altamente competitivo, onde havia a necessidade de fornecer o produto correto ao preço certo, utilizando, de maneira eficaz e eficiente, os recursos disponíveis, tanto humanos quanto materiais, para que pudessem proporcionar benefícios à sociedade, às empresas e ao governo de uma maneira que as instituições se mantivessem sustentáveis.

Baldridge e Deal (1993) e Meyer Jr. (1998), ao tentarem entender a natureza das organizações universitárias, destacaram aspectos que foram corroborados pelos sujeitos deste estudo, ou seja: a universidade tem objetivos ambíguos; é voltada para servir clientes; está centrada no trabalho de profissionais; possui produto de difícil mensuração; possui processo decisório e formas de gestão que mesclam aspectos burocráticos, políticos e colegiados; e, 


\section{A TRANSIÇÃO DE CONTRIBUIDOR INDIVIDUAL PARA LÍDER: A EXPERIÊNCIA VIVIDA PELO PROFESSOR UNIVERSITÁRIO}

somada à vulnerabilidade do ambiente em que se insere, é vista como organização complexa e paradoxal.

Os professores entrevistados, ao assumirem a gestão universitária, perceberam que estariam convivendo, pelo menos nos próximos quatro anos, com diversos desafios, como a natureza jurídica das universidades comunitárias e o fato de não possuírem garantia de recursos para o seu pleno funcionamento.

Somadas às características pertinentes às instituições fundacionais, cada uma das próreitorias que os professores entrevistados assumiram, seja de Administração, de Ensino, de Pesquisa e Extensão, possui suas especificidades. Os gestores sentiam-se constantemente desafiados por estarem assumindo uma estrutura já consolidada e em andamento, e por terem que intervir e se apropriar de conhecimentos diversos.

Eles se viam responsáveis pelos processos desenvolvidos na universidade, mas, ao mesmo tempo, não os conheciam o suficiente. Nenhum deles tinha se qualificado previamente para assumir a função de líder universitário, nenhum dos entrevistados possuía formação na área da gestão universitária, tampouco nas áreas das pró-reitorias que assumiram.

\subsubsection{A agenda do líder universitário}

Ao assumirem a gestão universitária, os professores sofreram o primeiro impacto: perceberam que o seu dia a dia era fragmentado, que a rotina era inexistente e o trabalho era intenso: "A agenda do reitor é incontrolável" (LUCAS). "Era um mergulho muito forte no trabalho, um envolvimento intenso, até porque a agenda não te permitia ser diferente, a agenda era lotada de atividades, compromissos" (RAFAEL).

Os ex-gestores consideram que o dia a dia da gestão universitária era imprevisível, pois as atividades se caracterizavam pela surpresa. Sempre aparecia uma reunião, um evento, algo que não fora planejado e onde tinham que estar presentes, a fim de representar a universidade. Esses professores foram constantemente atropelados por pequenos problemas.

Além de responderem pela reitoria ou pró-reitoria, ocupavam cargos inerentes às suas funções, tais como: presidentes ou membros dos conselhos universitários e membros do conselho de administração. Esse acúmulo de atividades, típico dos cargos ocupados, tornava a agenda desses gestores difícil de ser gerenciada. Raramente o planejado era executado, devido às demandas dos professores, alunos, enfim, da comunidade acadêmica.

Através das falas emprestadas pelos ex-gestores, fica evidente a realidade ressaltada por Mintzberg (1975), que, através das pesquisas conduzidas com gerentes, descobriu que 
estes profissionais estão envolvidos em inúmeras e variadas atividades, que normalmente não são padronizadas, além de serem de curta duração, prevalecendo a sua fragmentação e a reação.

Diante do contexto de trabalho vivido por esses ex-gestores, fica claro que a literatura clássica sobre a atividade gerencial não corresponde à realidade vivida por eles. Mintzberg (1975) argumenta que a proposta de Fayol, na qual os gerentes realizavam tarefas de previsão, organização, direção e controle, não condiz com a realidade dos gerentes. Essa proposta indica somente algumas atividades destes.

\subsubsection{O relacionamento interpessoal: a diversidade nas e das relações}

O relacionamento interpessoal é outro fator importante na prática gerencial (MINTZBERG, 1990). Diferentes foram as percepções dos entrevistados, no que se refere ao relacionamento mantido com os outros, durante a fase em que foram reitores ou pró-reitores. Os professores compreenderam que somente através dos relacionamentos mantidos com outras pessoas seria possível administrar a universidade, ainda que, em alguns momentos, esses relacionamentos fossem conflituosos e, em outros, uma relação amigável.

Resgatando suas experiências, fica evidente que os professores começaram a perceber a real diversidade da nova condição somente após terem assumido os cargos e enfrentarem a nova realidade: "[...] viver a diversidade na diversidade. Então, eu vivi uma diversidade todo dia. Cada aluno que aparece na sua frente, cada pessoa que aparece na sua frente, cada turbulência que aparece na sua frente, é um problema de ordem diferente. [...] é uma diversidade muito grande" (LUCAS).

Diante de tamanha diversidade, sentiam dificuldade de tomar decisão, pois diversos interesses, de diferentes grupos, deveriam ser levados em consideração: os dos professores, dos alunos, da comunidade externa e de técnicos administrativos. Os embates foram inevitáveis e consumiram muita energia. Diante desse desafio, eles aprenderam que o diálogo poderia ser a melhor forma de agregar, e que, se possível, antes de tomar a decisão, deveriam conhecer os diferentes interesses dos envolvidos, para evitar qualquer polarização de opiniões. Eles perceberam a importância do consenso e da necessidade de não tomarem decisões sozinhos

O aprendizado relacionado ao processo de tomada de decisão de forma colegiada foi significativo para esses professores. Eles acabaram por descobrir, no seu dia a dia, a partir do enfrentamento de diversas dificuldades, errando e acertando, formas mais apropriadas para 
alcançar os objetivos da instituição. A maioria dos professores não estava acostumada a procurar conhecer a percepção de outros sobre um fato, antes de tomar uma decisão.

Enquanto reitores e pró-reitores, eles tentaram se dedicar ao estabelecimento de relações com os professores e demais integrantes de suas equipes de trabalho, porém, a maior parte de seu tempo era dedicada às outras atividades de gestão. Perceberam que, necessariamente, a fim de lograrem êxito, precisavam se relacionar, se aproximar de outras diversas áreas da universidade.

Os ex-gestores, além das relações interpessoais estabelecidas com os professores, destacaram as vividas com os alunos. Essas relações foram permeadas por conflitos e reivindicações.

A família também fez parte da experiência vivida desses professores no período em que eram líderes universitários. Suas falas revelam que sentiram, ao mesmo tempo, apoio nos momentos em que necessitavam do aconchego do lar, e cobrança por maior tempo de dedicação à família.

\subsubsection{A falta da pesquisa e da sala de aula}

Ao assumirem a função de gestores, os professores se defrontaram com perdas, tais como o fato de terem se afastado da pesquisa universitária e da sala de aula. Por estarem absorvidos pela atividade de gestão, não conseguiram dar sequência aos seus projetos de pesquisa e viram suas produções acadêmicas diminuídas.

Os ex-gestores ressaltaram que um dos aspectos negativos da gestão é o afastamento das atividades docentes, mais especificamente, da sala de aula. "A perda, o aspecto negativo, é a saída da sala de aula, que acaba sendo inerente ao cargo" (MIGUEL). Samuel reforça os reflexos negativos percebidos, com o afastamento das atividades docentes.

Os estudos de Marra e Melo (2003) destacam que os professores que assumiram atividades de gestão de departamentos ou cursos diminuíram drasticamente as atividades de pesquisa e de docência. No caso dos reitores e pró-reitores, essa realidade também pode ser observada.

Os ex-gestores perceberam rapidamente a falta de contato mais direto com a docência e a falta de tempo para continuarem a investir nas suas produções acadêmicas, as quais só puderam retomar após deixarem o cargo. 


\subsubsection{Mudando o olhar: a necessidade da visão do conjunto}

Durante as entrevistas, os professores resgataram várias vezes que, ao assumirem a gestão das universidades, perceberam a importância de ter uma "visão do conjunto", uma "visão sistêmica", para que fosse possível realizar uma gestão universitária eficiente. Eles entenderam que olhar a universidade como professor é diferente de olhar a universidade como gestor:

Robert Katz, na década de 1970, já apontava a importância da "visão sistêmica" para os gestores de organizações (KATZ, 1986), algo que foi corroborado pelos professores, ao expressarem como foi a experiência de assumir a reitoria ou uma pró-reitoria de uma universidade.

Esses professores reconheceram que, ao atuarem na sala de aula, sentiam-se conhecedores desse universo, preocupavam-se com as relações estabelecidas com os alunos, com a atualização do conteúdo da disciplina lecionada e com os recursos necessários para uma melhor atuação docente. Passando a ser responsáveis pela gestão universitária, viram-se diante de um grande desafio e trataram rapidamente de conhecer a universidade como um todo: os departamentos, os projetos de pesquisa, de extensão, e a comunidade externa à instituição. Tal conhecimento foi mediado através das diferentes relações que conseguiram estabelecer com pessoas dos mais diferentes espaços da universidade.

\subsubsection{Buscando qualificação profissional: "um divisor de águas"}

Os professores entrevistados nesta pesquisa, ao assumirem a função de líderes universitários, em sua maioria sentiram a necessidade de conhecer as teorias sobre a Gestão Universitária e, para tanto, buscaram conhecimentos complementares frequentando cursos de especialização, fazendo leituras e contatos com outros professores que passaram por experiências semelhantes. Os ex-gestores buscaram cursos de especialização na área de Administração Universitária e em áreas específicas de suas pró-reitorias.

Eles possuíam conhecimentos de gestão empresarial, mas, durante suas gestões, perceberam que a universidade tem características distintas das empresas para as quais esse tipo de gestão pode resultar benéfica. Acreditavam que, através desses cursos específicos da gestão de instituições de ensino superior, poderiam realizar uma gestão mais profissionalizada, além de evitarem a sua rejeição por parte da comunidade acadêmica, pelo fato de não terem especialização nas áreas assumidas por eles. 


\section{A TRANSIÇÃO DE CONTRIBUIDOR INDIVIDUAL PARA LÍDER: A EXPERIÊNCIA VIVIDA PELO PROFESSOR UNIVERSITÁRIO}

Através dos relatos dos ex-gestores, ficou evidente a importância do conhecimento adquirido em cursos voltados ao ensino de práticas ligadas à gestão universitária. A qualificação proporcionada por esses cursos conferiu maior segurança aos professores para assumirem as responsabilidades do cargo.

Tamanha significância dada à qualificação é interpretada como a necessidade que os gestores tinham de se qualificar e buscar conhecimentos que respondessem às suas dúvidas em relação à gestão da universidade. Eles conseguiram isso não somente através de processos formais, tais como cursos de especialização, mas também através da interação social, e dos aprendizados oriundos dos erros e acertos no seu trabalho. Tal realidade vivida pelos exgestores entrevistados deste estudo foi corroborada por Silva (2002), que compreende que o processo de aprendizagem adotado por professores no exercício do cargo gerencial caracteriza-se como informal, autodirecionado, e que acontece no trabalho.

Inicialmente, eles desenvolveram a gestão universitária sem conhecimentos específicos, realidade corroborada pelos estudos de Rizzatti, Rizzatti Jr. e Sartor (2004), Piazza (1997) e Figueiredo (1992), ao destacarem que a administração de diversas universidades acontece de forma empírica, já que a maioria de seus gestores não possui conhecimentos teóricos sobre as funções administrativas. A literatura aponta que não é prática comum, nas universidades, a realização de investimentos em capacitação profissional para as funções gerenciais (PIAZZA, 1997; HEERDT, 2002; SILVA; MORAES; MARTINS, 2003; MARRA; MELO, 2003; CRUZ, 2008). Aqui fica evidente uma das fragilidades vividas pelas gestões do ensino superior: a falta de investimentos na qualificação dos professores que são escolhidos para ocupar cargos de liderança.

\subsubsection{O tempo: "meu inimigo número um"}

Através dos relatos dos ex-gestores, observamos que um dos grandes desafios que vivenciaram estava relacionado à percepção do tempo. Eles percebiam o tempo como se fosse seu inimigo número um, pois este parecia passar muito rapidamente, enquanto eles se sentiam impotentes por não conseguirem colocar em prática todos os seus projetos.

Ao lembrarem da percepção da falta de tempo para realizarem tudo o que gostariam de realizar, os ex-gestores expressaram a dificuldade que sentiam para atingir as metas planejadas.

Os ex-gestores percebiam o tempo passar de maneira veloz e, conforme destacaram nas entrevistas, o planejamento era difícil de ser cumprido, uma vez que eram inúmeras as 
situações que precisavam ser tratadas com urgência, e isso interferia na programação agendada.

Para diminuir a sensação da falta de tempo, que sentiam fortemente durante o mandato de gestores universitários, eles trabalharam incessantemente, cumprindo horários de trabalho sacrificantes. Para eles, existia somente o horário de início do trabalho.

Os ex-gestores perceberam a necessidade de aprender a gerenciar o tempo. Alguns, depois de sofrerem inicialmente com a falta de planejamento de seu tempo, perceberam que, quando conseguiam priorizar algumas atividades, também conseguiam concretizá-las sem o sentimento de falta de tempo.

É possível perceber que, diante das diversas demandas, de diferentes atores, havia a necessidade de priorizar as tarefas que deveriam ser executadas exclusivamente por eles. Assim, a necessidade de delegar tarefas também passou a ser um fator determinante para o cumprimento de todas as atividades pelas quais eram responsáveis.

Ésther (2007), em sua pesquisa com reitores, vice-reitores e pró-reitores de oito universidades federais localizadas no Estado de Minas Gerais, visualizou que os professores, ao assumirem cargos de gerência, em todos os níveis hierárquicos pesquisados, experimentaram a sensação e a prática de que suas atividades são repletas de repetições, papelada, agendas e problemas a serem resolvidos, o que dificultava o gerenciamento de seu tempo de trabalho e a priorização das atividades. Tal realidade não difere daquela encontrada nas organizações empresariais, já estudadas por Hill (2003) e Mintzberg (1973), e pela realidade vivida pelos professores participantes de nossa pesquisa.

\subsubsection{O ambiente de trabalho}

Ao serem questionados sobre suas percepções quanto ao ambiente/espaço de trabalho, alguns professores relacionaram as questões do espaço físico, tais como a distribuição do mobiliário, enquanto outros resgataram o ambiente psicológico em que viviam.

Miguel ressalta que seu ambiente de trabalho era percebido como muito tenso, sobretudo em função das decisões que deveriam ser tomadas: “[...] uma tensão muito grande, em função dos atrasos que nós vivenciamos, de salário, dos fornecedores. [...] o ambiente era um ambiente tenso, principalmente nos primeiros seis meses, muito tenso, muito carregado $[\ldots] . "$

Alguns realizaram mudanças no espaço físico durante suas gestões, com o propósito de melhor atender às pessoas que pudessem procurá-los. 
Lucas ressalta que, inicialmente, o espaço físico da reitoria era ruim. Posteriormente, um grupo de arquitetos se reuniu e elaborou um projeto de remodelação do espaço da reitoria. Ele confessa que, de início, o espaço projetado pelos profissionais lhe pareceu exagerado e, além disso, consumiria recursos importantes. No entanto, depois compreendeu a importância da grande reforma física.

O ambiente físico, para esses professores, foi um dos fatores mais lembrados ao falarem sobre o ambiente de trabalho. A configuração das salas, sua localização, as suas dimensões e a organização do ambiente de trabalho parecem interferir nos processos de trabalho.

\subsubsection{Sofrendo}

A categoria "sofrendo", por apresentar-se bastante significativa, fecha este capítulo em que resgato os temas centrais que representam as experiências que os professores viveram como reitores e pró-reitores.

As falas dos ex-gestores carregam consigo, embora nem sempre de maneira explícita, o sofrimento que permeou suas gestões, primordialmente no momento da tomada de decisão, na percepção das fragilidades de suas formações para ocuparem o cargo de gestores e nos relacionamentos interpessoais.

Tomar decisões que iam contra interesses de grupos, representou momentos de elevado nível de estresse e sofrimento para os professores. "O gestor universitário é um tomador de decisões, e isso era muito estressante, porque muitas das decisões eram difíceis porque, por exemplo, significava ir contra interesses de grupos e resolver problemas, isso foi difícil para mim.” (LUCAS).

O papel decisório, um dos papéis gerenciais preconizados por Mintzberg (1990), foi um dos maiores motivos de sofrimento para os gestores. Solucionar problemas, tomar partido a respeito de uma mudança necessária e responder constantemente às pressões organizacionais, configurou-se um sofrimento para eles.

Os entrevistados sofreram também por entenderem que não possuíam a formação adequada para ocupar a função gerencial, além do fato de a comunidade acadêmica perceber neles esta fragilidade. A comunidade acadêmica cobrava e colocava em xeque a competência de alguns ex-gestores, no processo de liderança universitária.

O sofrimento pelo qual os ex-gestores passaram durante o tempo de sua gestão, parece relacionado com a falta de conhecimentos gerenciais, sobretudo em relação às pastas pelas 
quais respondiam. A partir dessa percepção, passaram a buscar qualificação por meio de estudos, leituras e realização de algumas especializações, o que os tornou mais seguros e capazes de demonstrar sua competência à comunidade acadêmica.

Discutir a qualificação profissional de professores que podem atuar na gestão de instituições de ensino superior é papel fundamental dos atuais líderes dessas organizações. No contexto universitário, professores de diferentes formações podem atuar no gerenciamento dessas organizações, intervindo nas questões relacionadas à gestão de pessoas, projetos, recursos financeiros e materiais.

Os professores entrevistados nesta pesquisa sofreram ao se defrontarem com a fragmentação e a brevidade das tarefas típicas dos gestores, o que os fez dedicarem um tempo maior ao trabalho, em detrimento da quantidade de tempo dispensada às suas tarefas particulares e, sobretudo, à sua família. Essa situação demonstra, mais uma vez, a falta de preparo para viverem tal experiência.

Viver a diversidade das relações interpessoais também se configurou, ao menos inicialmente, um motivo de sofrimento para eles. Eles precisavam atender a diversas reivindicações, de diferentes grupos: professores, técnicos administrativos e alunos. Errando e acertando, aprenderam que uma atuação de forma colegiada era necessária para que alcançassem os objetivos mais adequados para a instituição.

Os professores deste estudo, ao assumirem a liderança universitária, incorporaram o compromisso com uma nova identidade pessoal, orientada para gerenciar pessoas e não apenas tarefas técnicas. Para Hill (2003), o processo de tornar-se gerente pode ser, na maioria das vezes, um processo cheio de tensões, de conflitos, de sofrimentos pessoais e de intensas emoções, o que gera estresse.

Tal realidade não estava clara, ao menos inicialmente, para os sujeitos desta pesquisa. Percebemos que não estavam preparados para enfrentar esta realidade, sobre a qual não tinham noção, e isto lhes causou tanto sofrimento inicial. No entanto, eles foram aprendendo com seus erros e acertos e buscando qualificação através de leituras e cursos de especialização.

\section{CONSIDERAÇÕES FINAIS}

A metodologia utilizada permitiu que os seis professores pudessem resgatar suas experiências vividas na transição de contribuidores individuais para líderes, de forma ainda pré-reflexiva, elucidando os temas envolvidos nesse período de suas vidas. À medida que os 


\section{A TRANSIÇÃO DE CONTRIBUIDOR INDIVIDUAL PARA LÍDER: A EXPERIÊNCIA VIVIDA PELO PROFESSOR UNIVERSITÁRIO}

professores recordavam suas histórias, foram conduzidos a um processo reflexivo, a fim de que os significados dessa experiência vivida viessem à tona.

Recorrendo às entrevistas transcritas, foi possível resgatar os temas centrais das experiências que os professores entrevistados viveram como reitores ou pró-reitores. Tais temas apresentaram-se da seguinte forma: a estrutura universitária: um dos desafios; a agenda do líder universitário; o relacionamento interpessoal: a diversidade nas e das relações; a falta da pesquisa e da sala de aula; mudando o olhar: a necessidade da visão do conjunto; buscando qualificação profissional: "um divisor de águas"; o tempo: "meu inimigo número um"; o ambiente de trabalho; e, sofrendo.

Compreendemos que a universidade tem um papel importante no processo de desenvolvimento humano, porque ela prepara, primordialmente, a geração de hoje para cuidar de gerações futuras. Pois sua maior meta é formar pessoas que possam, com seu trabalho, contribuir para o desenvolvimento da sociedade.

No entanto, essa mesma universidade que auxilia o processo de aprendizagem de pessoas, os seus alunos, às vezes se apresenta negligente no processo de acompanhamento de seus funcionários, como resgatado pelos professores que fizeram parte do nosso estudo.

Percebemos, por meio das constatações apresentadas pelos sujeitos significativos deste estudo, que há carência de apoio e assistência na condução dos professores para os cargos de gestão universitária. Apesar de a transitoriedade ser algo corriqueiro no ambiente universitário, essas questões não estão sendo levadas em consideração pela gestão dessas instituições de ensino superior.

A compreensão da transição como um processo que envolve ganhos e perdas poderá ser ampliada ou aprofundada por meio de outros estudos que enfoquem tal temática e, sobretudo, através do acompanhamento desse processo por parte do departamento de recursos humanos destas universidades.

Uma instituição universitária deve ter objetivos abrangentes, em relação à satisfação ou adaptação dos seus docentes, no sentido de incluir, em seu planejamento, a preparação e o acompanhamento dos professores em vias de transição, oferecendo-lhes oportunidades de formação que facilitem a continuidade de seu crescimento e sua satisfação pessoal. Diante dessa realidade, faz-se necessário buscar modelos inovadores de gestão de pessoas, para enfrentar as constantes transições requeridas dos professores universitários.

As universidades nas quais os sujeitos significativos deste estudo viveram suas transições não os apoiaram e não os auxiliaram nesse processo, o que nos leva a crer que 
possivelmente tal realidade esteja sendo vivenciada também em outras instituições de ensino superior.

Essas universidades ainda se ressentem de uma administração adequada às suas peculiaridades. Elas geralmente tendem a adotar os mesmos modelos empregados nas organizações públicas e privadas, sem levar em consideração as especificidades próprias de uma instituição complexa e com objetivos múltiplos e especializados, voltados para a criação e difusão do conhecimento (GRILLO, 1991).

Os dirigentes, entre eles, os servidores técnicos, docentes e outros administradores, representam a base de sustentação da instituição. Por isso as universidades precisam desenvolver políticas e princípios que orientem seus servidores e lhes garantam o seu contínuo desenvolvimento profissional e pessoal, para que estejam motivados e preparados para o desempenho das atividades diversas, contribuindo para a melhoria da qualidade final na instituição. Pois é indispensável contar com pessoal preparado e capacitado para atender às peculiaridades da instituição.

Tais conclusões reforçam a importância de se aprofundar, cada vez mais, os estudos relativos à gestão das pessoas que trabalham nas instituições universitárias.

Nossa recomendação, a respeito da criação de fóruns que discutam a transição dos professores nas diversas funções desempenhadas na universidade, relaciona-se, acima de tudo, com a esperança de que este estudo possa conduzir à realização de muitos outros, tendo em vista a relevância social do tema.

As universidades devem se preparar para novos desafios, principalmente dando maior atenção à gestão das pessoas, no sentido de propiciar condições adequadas para que elas realizem suas funções de maneira harmoniosa, eficiente e eficaz, num clima de desenvolvimento coletivo e mútuo.

\section{REFERÊNCIAS}

BALDRIDGE, J. V.; DEAL, T. Dynamies of organizational change in education. Berkeley: Mcutchan Publishing Corporation, 1993.

BENNIS, W. A invenção de uma vida. Rio de Janeiro: Campus; São Paulo: Publifolha, 1999.

BRIDGES, W. Managing organizational transitions. Organizational Dynamics, Summer, 1986, p. 24-33. 
CRUZ, R. C. Tipos de atividades que constituem as rotinas do trabalho de diretores de cursos de graduação de uma universidade e aprendizagens para o exercício da função. 2008. 219 f. Tese (Doutorado) - Programa de Pós-Graduação em Psicologia, Centro de Filosofia e Ciências Humanas, Universidade Federal de Santa Catarina, Florianópolis, 2008.

CUNHA, L. A. Reforma universitária em crise: gestão, estrutura e território. In: TRINDADE, H. (org.). Universidade em ruínas: na república dos professores. Petrópolis: Vozes, Rio de Janeiro: CIPEDES, 1999.

DE VRIES, M. F. R. K. The dark side of CEO succession. Harvard Business Review. Boston: v. 66, n. 1, jan./feb.,1988.

DUBERLEY, J.; MALLON, M.; COHEN, L. Exploring career transitions: accounting for structure and agency. Personnel Review, v. 35, n. 3, p. 281-296, 2006.

ÉSTHER, A. B. A construção da identidade gerencial dos gestores da alta administração das universidades federais em Minas Gerais. 2007. 276 f. Tese (Doutorado em

Administração) - Faculdade de Ciências Econômicas, Universidade Federal de Minas Gerais, Belo Horizonte, 2007.

ÉSTHER, A. B.; MELO, M. C. de O. L. A construção da identidade gerencial dos gestores de alta administração de universidades federais em Minas Gerais: o caso dos reitores. In: ENCONTRO NACIONAL DOS PROGRAMAS DE PÓS-GRADUAÇÃO EM ADMINISTRAÇÃO, 31., 2007, Rio de Janeiro. Anais... Rio de Janeiro: ENANPAD, 2007. 1 CD-ROM.

FIGUEIREDO, R. S. A tomada de decisão por dirigentes universitários: um estudo comparativo em universidades pública, comunitária e empresarial. 1992. 240 f. Dissertação (Mestrado em Administração) - Centro Sócio Econômico, Universidade Federal de Santa Catarina, Florianópolis, 1992.

FINGER, A. P. Liderança e gestão universitária. In: Finger A. P. et al. Liderança e administração na universidade. Florianópolis: OEA/UFSC, p. 13-26, 1986. 1988.

Universidade: organização, planejamento e gestão. Florianópolis: Editora da UFSC,

GLASER, B. G.; STRAUSS, A. L. The discovery of grounded theory: strategies for qualitative research. New York: Aldine de Gruyter, 1967.

GRILLO, A. N. Desenvolvimento de pessoal nas universidades: em busca da qualidade do ensino superior. Florianópolis: Insular, 1991.

HEERDT, A. P. S. Competências essenciais dos coordenadores de curso em uma instituição de ensino superior. 2002. 100 f. Dissertação (Mestrado em Engenharia de Produção) - Programa de Pós-Graduação em Engenharia de Produção, Universidade Federal de Santa Catarina, Florianópolis, 2002. 
HESBURGH, T. M. A relevância dos valores no ensino superior. Brasília: Universidade de Brasília, 1982.

HILL, L. A. Become a manager: how new managers master the challenges of leadership. 2. ed. Harvard Business School Press, 2003.

HOWARD, C. A. From engineer to engineering manager: a qualitative study of experiences, challenges, and individual transitions for engineering managers in aerospace companies. A Thesis in Workforce Education and Development. Degree of Doctor of Philosophy.The Pennsylvania State University - The Graduate School - Department of Adult Education, Instructional Systems, and Workforce Education and Development. August 2003.

KANAN, L. A. Características do processo de vinculação de coordenadores de curso com o trabalho e com a universidade. 2008. 258 f. Tese (Doutorado em Psicologia) Programa de Pós-Graduação em Psicologia, Universidade Federal de Santa Catarina, Florianópolis, 2008.

KATZ, R. As habilitações de um administrador eficiente. Coleção Harvard de Administração. v. 1, p. 57-92. São Paulo: Nova Cultural, 1986.

KERR, C. Os usos da universidade. Fortaleza: Edições UFC, 1982.

KINICKI, A. J.; PRUSSIA, G. E.; MCKEE-RYAN, F. M. A panel study of coping with involuntary job less. Academy of Management Journal, v. 43, n.1, p. 90-100, feb., 2000.

KONCZAK, L. J. The first-time manager. Personnel Psychology, Summer, v. 47, n.2, 1994.

LATACK, J. C.; KINICKI, A. J; PRUSSIA, G. E. An integrative process model of coping with job loss. The Academy of Management Review, v. 20, n. 2, apr. 1995.

MARRA, A. V; MELO, M. C. O. L. Docente-gerente: o cotidiano dos chefes de departamento e coordenadores de curso em uma Universidade Federal. In: ENCONTRO NACIONAL DOS PROGRAMAS DE PÓS-GRADUAÇÃO EM ADMINISTRAÇÃO, 27. 2003, Atibaia. Anais... Atibaia: ENANPAD, 2003. 1 CD-ROM.

A prática social de gerentes universitários em uma instituição pública. Revista de Administração Contemporânea, v. 9, n. 3, p. 9-31, jul./set. 2005.

MEYER JR., V. Gestão para a qualidade e qualidade na gestão: o caso das universidades. Cadernos - Centro Universitário São Camilo. São Paulo, v.4, n. 1, p. 49-59, jan./jun. 1998.

. Novo contexto e as habilidades do administrador universitário. In: MEYER JR., V.; MURPHY, J. P. Dinossauros, gazelas e tigres. Florianópolis: Insular, 2000. MINTZBERG, H. The nature of managerial work. New York: HarperCollins Publishers, 1973.

The manager's job: folklore and fact. Harvard Business Review, v. 5, n. 4, p. 49-61, jul./aug. 1975.

The manager's job: folklore and fact. Harvard Business Review, v. 68, n. 2, mar./apr. 1990. 
MORAES, L. V. dos S. de. A trajetória de mulheres que se tornaram reitoras em instituições de ensino superior no Estado de Santa Catarina. 2008. 240 f. Tese (Doutorado em Engenharia de Produção) - Centro Tecnológico, Universidade Federal de Santa Catarina, Florianópolis, 2008.

MORGAN, G. Paradigms, metaphors and puzzle solving in organization theory. Administrative Science Quartely, v. 25, p. 605-622, 1980.

NININGER, J. R.; ARDITTI, M. J. A renovação das organizações: gerenciando transições na força de trabalho. Cadernos ENAP, 28. 92 p. Brasília: ENAP, 2004.

PEARCE II, J. A. Problems facing first-time managers. Human Resource Management, 21, 1, Spring 1982.

PEARCE, C; CONGER, J. Shared leadership: reframing the hows and whys of leadership. Thousand Oaks: Sage, 2003.

PIAZZA, M. E. O papel das coordenações de cursos de graduação segundo a percepção de coordenadores em exercício da função. 1997. 213 f. Dissertação (Mestrado em Educação) - Universidade Federal de São Carlos, São Carlos, 1997.

REZENDE, A. M. de. O saber o poder na universidade: dominação ou serviço? São Paulo: Cortez, 1982.

RIZZATTI, G.; RIZZATTI JR., G.; SARTOR, V. V. B. Categorias de análise de clima organizacional em Universidades Federais. IV COLÓQUIO INTERNACIONAL SOBRE GESTÃO UNIVERSITÁRIA NA AMÉRICA DO SUL, Florianópolis (SC), 2004. Anais... [CD-ROOM].

SARGENT, A. G; SCHLOSSBERG, N. K. Managing adult transitions. Training \& Development Journal. v. 42, n. 12, dec., 1988.

SCHLOSSBERG, N. K. A model for analysing adaption to transition. The Counseling Psychologist, v. 9, n. 2, p. 2-18, 1981.

SEIDMAN, Irving. Interviewing as qualitative research. New York: Teaches College Press, 1998.

SILVA, M. A. da. A aprendizagem de professores da Universidade Federal de Santa Catarina para dirigir as unidades universitárias. 2000. $268 \mathrm{f}$. Tese (Doutorado em Engenharia de Produção e Sistemas) - Centro Tecnológico, Universidade Federal de Santa Catarina, Florianópolis, 2000.

SILVA, M. G. R. Competências gerenciais dos coordenadores do curso de graduação em administração de empresas: um estudo de caso na UCS. In: ENCONTRO NACIONAL DOS PROGRAMAS DE PÓS-GRADUAÇÃO EM ADMINISTRAÇÃO, 26, 2002, Salvador. Anais... Salvador: ENANPAD, 2002. 1 CD-ROM.

SILVA, M. A. da; MORAES, L. V. S. Como os professores aprendem a dirigir unidades universitárias: o caso da UFSC. In: ENCONTRO NACIONAL DOS PROGRAMAS DE 
PÓS-GRADUAÇÃO EM ADMINISTRAÇÃO, 26, 2002, Salvador. Anais... Salvador: ENANPAD, 2002. 1 CD-ROM.

SILVA, M. A.; MORAES, L. V. S.; MARTINS, E. S. A aprendizagem gerencial dos professores que se tornam dirigentes universitários: o caso da UDESC. In: ENCONTRO NACIONAL DOS PROGRAMAS DE PÓS-GRADUAÇÃO EM ADMINISTRAÇÃO, 27. 2003, Atibaia. Anais... Atibaia: ENANPAD, 2003. 1 CD-ROM.

SILVA, F. M. V. da. A transição de líder para contribuidor individual: a experiência vivida pelo ser gestor universitário. 2011. $273 \mathrm{f}$. Tese (Doutorado em Engenharia de Produção) - Centro Tecnológico, Universidade Federal de Santa Catarina, Florianópolis, 2011.

STOGDILL, R. M. Handbook of leadership: a survey of theory and research. New York: Free Press, 1974.

TACHIZAWA, T; ANDRADE, R. O. B. de. Gestão de instituições de ensino. Rio de Janeiro: Editora Fundação Getúlio Vargas, 1999.

THOMAS, J. Handbook for first-time managers: managing effectively. Women in Business, v. 51, n.1, jan./feb., 1999.

TRIGUEIRO, M. G. S. Universidades públicas: desafios e possibilidades no Brasil contemporâneo. Brasília: Editora Universidade de Brasília, 1999.

VAN MANEN, M. Researching lived experienced. London, Ontário: The Althouse Press, State University of New York Press, 1990.

ZIKIC, J.; RICHARDSON, J. Unlocking the careers of business professionals following job loss: sensemaking and career exploration of older works. Canadian Journal of Administrative Sciences, 24, 1, mar 2007. 